\title{
Acción gremial de base y precariedad laboral en la industria Argentina: repaso de algunas experiencias
}

\author{
Gabriela Wyczykier \\ Doctora en Ciencias Sociales (FLACSO-sede Argentina) \\ Investigadora-docente de la Universidad Nacional de General Sarmiento \\ Investigadora del Consejo Nacional de Ciencia y Tecnología (CONICET) \\ gwyczykier@yahoo.com
}

\begin{abstract}
Resumen
El presente artículo analiza las demandas y acciones sindicales de base en torno a la problemática de la precariedad laboral que emergieron en el sector industrial de la economía Argentina en el milenio actual. Se propone analizar esencialmente en qué sentidos, con qué atributos, potencialidades y limitaciones se han desarrollado demandas y acciones conflictivas en torno a esta temática fomentadas por delegados y trabajadores de base. Esta inquietud reconoce la importancia de un contexto caracterizado por la revitalización de los conflictos sindicales y la persistencia de modalidades de integración socio-laboral desiguales al interior de los colectivos laborales.

En virtud de esta preocupación, se presenta el análisis de cuatro colectivos de base en la industria que han afrontado las demandas y acciones sobre la problemática de la precariedad, en particular, con respecto a los contratos de trabajo eventuales y los trabajadores. Estos colectivos forman parte del sector metalúrgico y de alimentos.
\end{abstract}

Palabras claves: precariedad laboral; demandas y acción colectiva; sindicalismo de base; sector industrial; Argentina.

\section{Introducción}

T a Argentina ha experimentado en el milenio actual, luego Lde la crisis sistémica que se cristalizó en diciembre del año 2001 ${ }^{1}$, la vitalización de las protestas sociales y en particular, a partir del año 2004 en adelante de los conflictos sindicales.

Ello en un marco de redefinición de las relaciones de fuerza que atraviesan y estructuran las instituciones políticas del país y aún más, del reposicionamiento que adquirió fundamentalmente una de las centrales obreras argentinas (la Confederación General del Trabajo) que configuró una alianza estratégica entre el movimiento obrero y el partido de gobierno ${ }^{2}$.

De este modo, en una contexto de trasformación de algunas variables políticas claves del modelo de acumulación neoliberal de la dé-

1 El carácter sistémico de esta crisis se vincula con sus efectos combinados sobre dimensiones económicas, políticas y sociales.

2 La otra central obrera que agrupa fundamentalmente gremios estatales y otros sindicatos, pero que no ha logrado obtener hasta la actualidad la personería gremial es la Central de Trabajadores Argentinos (CTA). 
cada anterior, pero también en la continuidad de algunas de las mismas, se reconoce la importancia del aumento del empleo y la disminución del desempleo, el crecimiento de la economía y la reversión del proceso de desindustrialización que caracterizara las décadas antecedentes ${ }^{3}$, jugaran en el fortalecimiento de las organizaciones sindicales en sus distintos niveles de agregación (de base, seccionales, uniones, federaciones, centrales) para reposicionar nuevamente en el universo de las protestas sociales a los conflictos laborales y gremiales.

Si bien las disputas sindicales han estado mayormente ligadas a las demandas económicas, es advertible que otras situaciones problemáticas entre trabajo y capital, o entre las propias estructuras de representación gremial existentes, han configurado estos conflictos, aunque con distinto nivel de visibilidad con respecto a las disputas fundamentalmente salariales.

La precariedad laboral, por otro lado, ha sido una modalidad de inserción sociolaboral presente en las relaciones salariales del modelo de acumulación capitalista en distintos momentos históricos de consolidación de este modelo y en diversas geografías nacionales. Sin embargo su significación estadística, política y en cuanto a su presencia en la literatura académica y militante, se inscribe fundamentalmente a partir de mediados de los años 1970 en adelante en el marco de las transformación capitalistas que definen el pasaje de una lógica predominante de relaciones laborales de la era fordista, a otra denominada postfordista y/o postindustrial.

En esta orientación, Harvey (2004) se inquieta por este proceso de transición en el régimen de acumulación y su correspondiente modo de regulación social y política. Así, el pasaje de un modo de regulación de las relaciones sociales y laborales caracterizado por el fordismo y la plenitud de la sociedad industrial omnipresente, dio lugar a un sistema que apela a la flexibilidad de los procesos de trabajo y que ha generado significativos efectos sobre las modalidades de vinculación de los individuos con el empleo y el mercado laboral (informalidad, precariedad, subempleo, desempleo) La precariedad laboral no resulta en este sentido una modalidad novedosa y sin anclaje histórico en las relaciones laborales capitalistas.

Como bien introducen Alvater y Mahnkopf (2008), las relaciones laborales precarias y por tanto no normadas en la era fordista, fueron absorbidas por el sistema industrial o desplazadas hacia pequeñas subempresas, actividades de la agricultura, el comercio minorista, sobre todo en los países subdesarrollados. Sin embargo, en la era de la globalización, la precariedad laboral vuelve a resituarse en los mercados capitalistas desarrollados. Ello conduce a profundizar las desigualdades socioestructurales de poder entre capital y trabajo, analizan los autores, porque se oponen a las garantías y la seguridad social e institucional que resultan de la relación normal de trabajo. Esta relación laboral brinda una seguridad vinculada a la dependencia y la subordinación por la permanencia y pertenencia de los trabajadores a una rama profesional por un tiempo indeterminado. Sin que ello mine las asimetrías de poder entre capital y trabajo, se configuran formas de solidaridad ligadas a los convenios colectivos y los seguros sociales.

De este modo, en la agenda académica se instauró desde los años 1970 un consenso sobre la contemplación del trabajo precario como 'atípico' y opuesto al trabajo regular estable asalariado, caracterizado por la seguridad y predictibilidad normativa. Si bien se reconoce su carácter heterogéneo, complejo, y ambiguo, el trabajo precario se visualiza como aquella modalidad de inserción ocupacional que se desvía de la norma. De todos modos se advierten variadas formas de inserción laboral precaria. Ello supone una multiplicidad de elementos involucrados para definirla, unidos éstos a la inestabilidad, la falta de protección, la inseguridad, la vulnerabilidad social y económica. Aquello que identifica entonces a la precariedad es una combinación de estos factores "y los límites del concepto son, inevitablemente, arbitrarios hasta cierto punto" (Rodgers, 1992, p. 19). Estos elementos suponen cierta ambigüedad al momento de observar los trabajos precarios, así como resulta significativamente variable la forma que en estos trabajos "atípicos" resultan precarios (Rodgers, 1992) 4 .

Estas modalidades de inserción laboral han afectado, como bien destaca parte de la bibliografía, la solidaridad en torno a los vínculos de trabajo que pueden favorecer la acción colectiva y reivindicativa de la clase trabajadora. Robert Castel (2000) se inquieta respecto a cómo los fenómenos del desempleo y la precariedad ha contenido efectos sobre la clase obrera y pueden operar sobre sus formas de acción colectiva. Ambos fenómenos han contendido efectos desestructurantes sobre este colectivo al haber quebrado homogeneidades intra e intercategoriales, favoreciendo la ruptura de solidaridades que otrora permitían a estos sujetos vincularse en situaciones laborales compartidas y reunirlos en acciones conjun-

3 Para el segundo trimestre de 2005 la tasa de desocupación era de un 12,1\%, siendo en igual período de 2010 del 7,9 (Indec).

4 La precariedad laboral como bien destacan Feldman y Galín (1990) puede caracterizar al empleo clandestino (empleo no registrado); al empleo a tiempo parcial; al empleo temporario; al empleo asalariado fraudulento. Esta clase de empleos ha tendido a acrecentarse desde los años 70 en las economías occidentales como consecuencia de los procesos de externalización productiva, terciarización y subcontratación de actividades y servicios por parte de las empresas. 
tas. Esta transformación entraña de este modo para Castel un proceso de descolectivización de las condiciones laborales y del modo de organización de los trabajadores, observándose como contrapartida un proceso de individualización de las estrategias personales para afrontar los riesgos descriptos, y permanecer integrados en relaciones de trabajo asalariadas formales. De tal forma, a los problemas ligados a la desigualdad masiva que se instala entre asalariados de la misma categoría laboral incentivada por el desempleo, se suman adicionalmente las provenientes de la difusión de formas atípicas de empleo, el trabajo parcial, intermitente, nuevas formas de trabajo independiente, entre otras.

Con este marco y espíritu analítico, en este artículo presentaremos algunos enunciados y argumentos que son el resultado de una investigación en la que nos hemos propuesto observar y caracterizar las demandas, los sentidos y las acciones gremiales de base con referencia a la precariedad laboral, en un escenario configurado por la vitalización de los conflictos sindicales. En este modo, no estaremos depositando nuestra mirada analítica sobre los procesos de fragmentación y descolectivización que ha afectado a la clase obrera desde varias décadas antecedentes, sino que, por el contrario, buscaremos destacar las características, potencialidades y limitaciones de acciones solidarias en el ámbito productivo en torno a una serie de experiencias atravesadas y condicionadas por el proceso de individualización de la trayectoria profesional.

El planteo de esta problemática en el sector de la industria en particular obedeció a un conjunto de elementos que nos estimularon en esta elección, entre los cuales se destacan, en el período de la postconvertibilidad, el crecimiento económico, el mejoramiento relativo de algunas variables sociolaborales como el descenso significativo del desempleo, la vitalización de los conflictos sindicales, la persistencia de modalidades diferentes de inscripciones ocupacionales en el lugar de trabajo, la presencia de trabajadores organizados en comisiones internas y cuerpos de delegados. Al mismo tiempo y como bien destacan Azpiazu y Schorr (2010), en estos años se advierte en este sector un proceso de profundización en la fragmentación de la clase obrera argentina debido a la presencia de trabajadores empleados con modalidades precarias de contratación y remuneraciones reducidas en relación a los trabajadores que gozan de empleos registrados y perciben mejores salarios, conformando ello una nueva dimensión de la diferenciación.

La investigación que inspira este artículo se ha realizado con una orientación cualitativa de investigación social, a través de la elección de 4 casos de estudio correspondientes a colectivos de base que forman parte del sector industrial de la economía, y que han encarado fundamentalmente desde el año 2001 en adelante algunas demandas y acciones en torno a la problemática de la precariedad laboral, estimuladas por delegados gremiales y trabajadores más activos en el lugar de trabajo ${ }^{5}$.

\section{Las acciones gremiales de base y la precariedad laboral: ilustración de algunas experiencias}

La precariedad laboral como bien destacan Feldman y Galín (1990) puede caracterizar distintas modalidades consideradas "atípicas" de integrar el mundo del trabajo: el empleo clandestino (empleo no registrado); el empleo a tiempo parcial; el empleo temporario; el empleo asalariado fraudulento.

Esta clase de empleos ha tendido a acrecentarse desde los años 1970 en las economías occidentales como consecuencia de los procesos de externalización productiva, terciarización y subcontratación de actividades y servicios por parte de las empresas.

En términos generales, ha medido estadísticamente la precariedad laboral en función del trabajo 'no registrado', si bien es advertible que el primero resulta de una mayor amplitud que el no registro del trabajo asalariado, ligado éste a la no realización de aportes al sistema de seguridad social por parte de los empleadores y tomadores de fuerza de trabajo para llevar adelante el proceso laboral ${ }^{6}$. En efecto, legalidad e ilegalidad contractual resultan límites difusos para establecer las características del trabajo precario dado que, luego de una serie de reformas en la regulación que afectan los vínculos laborales, un contrato

5 Es importante destacar que la elección de los casos no obedeció de ningún modo a una lógica por procurar algún tipo de representación con respecto a un fenómeno más amplio, sino que, por el contrario, hemos llegado a estos casos por el interés que inviste en el estudio analizar acciones gremiales y precariedad laboral en el sector de la industria, considerando que este tipo de situaciones no se han observado mayoritariamente entre las acciones gremiales más generales. Durante el trabajo de campo hemos desarrollado un conjunto de entrevistas en profundidad a delegados gremiales y trabajadores más activos respecto a la problemática de la precariedad. Las mismas fueron realizadas entre los años 2008 y 2009. 6 Las cifras de la Encuesta Permanente de Hogares - EPH - muestran que en el primer trimestre del año 2005, los trabajadores asalariados no registrados en la Argentina representaban el 47,5\%, mientras que en igual período del año 2010 esta cifra descendió al 34,6\% (Informe Estadístico del Tel, junio 2010). 
de trabajo previsto legalmente puede ser considerado al mismo tiempo precario ${ }^{7}$.

Ello se notó especialmente en el caso de las demandas y acciones encaradas por colectivos basistas en el sector industrial en torno a la precariedad, en las cuales se le otorgara una prioridad especial a los contratos eventuales y por agencia de empleo, así como a los trabajadores tercerizados ${ }^{8}$.

En este sentido, cabe señalar que la diversificación contractual ha instalado en el seno de los espacios productivos industriales, situaciones diferentes de inserción colectiva que ha afectado significativamente la organización gremial en el lugar de trabajo. De esta manera, y como una tendencia progresiva desde los años 90 en el país, se observa la convivencia y cooperación productiva en un mismo espacio laboral de trabajadores con modalidades diferentes de transitar su experiencia profesional y de conformar su trayectoria laboral.

Esta situación problemática, si bien advertida en parte por la bibliografía académica y por algunos representantes gremiales, no ha dinamizado con frecuencia acciones sindicales que hubieran colocado como una demanda generalizable de las organizaciones obreras las disputas en torno a esta condición. Varias razones de peso pueden esgrimirse al respecto: la situación de desempleo que afectó a la fuerza de trabajo y a sus organizaciones colectivas en los años 90 principalmente y continúa configurando los temores populares, el ingreso generaciones más jóvenes en los espacios de trabajo sin experiencia sindical y política, la naturalización de esta diversa manera de atravesar contractualmente la experiencia de trabajo por parte de los colectivos laborales, la limitación de las organizaciones sindicales más amplias por incorporar esta situación entre las disputas que atraviesan los vínculos antagónicos entre trabajo y capital.

Con referencia a los casos indagados, éstos se caracterizan por ser lugares de trabajo atravesados y configurados por la dinámica política sindical, en los cuales las demandas y acciones contra la precariedad han emergido inspiradas desde los delegados y trabajadores de base, tímidamente acompañadas, otras neutralizadas, o contrarrestadas por las seccionales gremiales, y el sindicato. Ello le asigna a estas demandas su carácter atomizado y particular: la precariedad devino demanda desde colectivos de base, sin encontrar en las organizaciones sindicales más amplias - salvo pocas excepciones - alguna repercusión o inspiración para operar activamente sobre las situaciones denunciadas, $\mathrm{y}$ en este camino transformar una demanda que surgió acotada a ciertas fábricas en particular en demanda sindical mas general.

Desde la percepción de militantes y delegados de los trabajadores en el sector industrial que han promovido acciones en torno a este tema, la definición de precariedad reconoce una amplitud que engloba un conjunto de dimensiones no ligadas exclusivamente a las modalidades de contratación. La misma se relaciona no tan sólo con las desigualdades que este tipo de inserción genera en el colectivo de trabajadores, sino también está vinculada, en muchos casos, a las condiciones de trabajo que afectan la salubridad. Así, la precariedad laboral caracteriza diferentes maneras de estar en el lugar de trabajo - afectando a ciertos grupos en particular - pero también caracteriza las condiciones en las cuales el proceso productivo de desenvuelve, con múltiples consecuencias sobre esos mismos grupos, y abarcando incluso la situación de aquellos que gozan de alguna estabilidad laboral. De todos modos son las condiciones contractuales las que han favorecido las medidas colectivas encaradas. Eso es un rasgo singular del milenio actual, siendo las demandas por condiciones de trabajo que afectan la salud física y mental de los trabajadores en virtud de la reproducción de mecanismos de explotación del capital sobre el trabajo, una situación advertible en la historia del movimiento obrero argentino e internacional.

\section{Los trabajadores metalúrgicos}

Los colectivos de trabajo de las empresas metalúrgicas Tenaris-Siat y Siderar-Morón, encararon en la década actual una serie de medidas para demandar por las contrataciones eventuales y la situación de los trabajadores tercerizados. En estos dos casos se observa al mismo tiempo una relación con el sindicato diferente y que nos permite ilustrar algunos de los argumentos señalados.

Los trabajadores de Tenaris-Siat ${ }^{9}$ afrontaron un conjunto de demandas y medidas para hacer frente a las contrataciones precarias especialmente desde el año

7 La extensión de la flexibilización contractual a partir de la década del 90 en el país, como analiza Perelman (2001) que se llevó adelante con la sanción de la Ley 24.013 del año 1991 y la sanción de la Ley 24.465 de 1995 extendieron las modalidades promovidas de empleo que contribuyeron a precarizar las relaciones de trabajo.

8 A partir de los años 1980 y los años 1990 particularmente, se extendió progresivamente en la Argentina la modalidad de inserción laboral vinculada con el "trabajador eventual", a través fundamentalmente de las agencias de trabajo temporario. Durante el actual milenio, el sector manufacturero ha sido uno de los principales demandantes de este tipo de contrataciones.

9 Esta planta pertenece a una empresa multinacional dedicada a la fabricación de tubos con y sin costura Se encuentra ubicada en la localidad de Valentín Alsina, Provincia de Buenos Aires. En el año 2008 el plantel estaba conformado por 340 trabajadores. 
2002 en adelante; cuando hubo una renovación de los delegados de sector y de la comisión interna. Una calcomanía que recibió quien escribe estas líneas a propósito de un encuentro con uno de los trabajadores más comprometidos en esta causa, anuncia "Tenaris Siat. NO A LA PRECARIZACIÓN", sobre uno de los lados de este anuncio "SÍ A LA EFECTIVIZACIÓN", sobre otros de los costados, impreso en letras negras sobre el logo de la Unión Obrera Metalúrgica. Ésta era una demostración traducida en palabras y en campaña sobre un problema poco conocido entre las organizaciones gremiales en sus distintos niveles de representación.

Al igual que muchas otras empresas del sector y de la economía argentina, durante los años 1990 hubo un importante proceso de tercerización en la planta y de contrataciones eventuales a través de agencias de empleo temporario ${ }^{10}$. Estas últimas tendieron a ser prorrogadas por un tiempo significativamente mayor que lo previsto por el marco regulatorio, siendo ello una práctica habitual incluso durante el milenio actual. Si bien esta condición inquietaba a delegados y trabajadores en aquellos años, las medidas colectivas impulsadas para afrontar la precariedad comenzaron a dinamizarse con el cambio de la Comisión Interna (CI), conformada por algunos delegados más jóvenes y otros con trayectoria política en la fábrica.

En el año 2003, las medidas contra la precariedad comenzaron entonces a cobrar mayor presencia. Entre las situaciones advertidas por este grupo de delegados y trabajadores con un mayor activismo gremial, que requerían atención de parte de una estrategia de confrontación colectiva pone de relieve la desigualdad en la percepción de beneficios entre contratados y efectivos. Ello se traducía no solamente en la percepción de salarios y premios diferentes, menores para los primeros que para los segundos, sino además en la imposibilidad de acceder a la colonia de vacaciones, medicamentos y juguetes que daba la empresa como beneficio a sus trabajadores efectivos.

Estas desigualdades de acceso se revirtieron desde aquél año a través de distintas estrategias: realización frecuente de asambleas, asistencia periódica a la seccional gremial (UOM Avellaneda) que luego de varias insistencias atendiera sus reclamos. Si bien para llevar adelante estas medidas los trabajadores no emprendieron ninguna acción colectiva de confrontación directa, la amenaza a la empresa con el quite de colaboración (no realización de horas extras), la movilización de la CI y los delegados por estas cuestiones problemáticas, y las distintas maneras de ejercer presión, se conjugaron para obtener los logros en relación a la equiparación de los beneficios económicos y salariales. La empresa en este sentido fue realizando concesiones paulatinas, atentos a los planteos del colectivo laboral.
La confrontación de cara a la empresa no era la única estrategia que hubo de llevar adelante la CI, los delegados de sector y trabajadores más activos respecto a la problemática de los trabajadores contratados. Al igual que ocurriera en otros casos indagados, al interior del colectivo de trabajadores la tarea de socializar, concientizar y generar un compromiso políticogremial de los trabajadores efectivos con respecto a los contratados, devino en un proceso de significativa presencia por parte de los delegados y trabajadores más comprometidos inicialmente con esta causa.

Ello es un rasgo común en las distintas experiencias estudiadas: reconfigurar vínculos solidarios entre trabajadores con distintas modalidades de contratación requirió de una tarea cotidiana de concientización de parte de estos delegados y trabajadores más activos, ya que la desigualdad en los recursos materiales percibidos se traducía conjuntamente en tratos diferenciados, tanto por parte de la empresa como al interior del propio colectivo laboral.

En principio, entre los trabajadores efectivos y contratados se estableció una relación distante, de competencia muchas de las veces por el temor de los primeros de ser reemplazados por los segundos, y de cierta sensación de abuso por parte de los contratados al tener que realizar tareas que los trabajadores efectivos ya no querían desarrollar. La rotación de los trabajadores generaba por otro lado serias dificultades en varias empresas para consolidar vínculos de compañerismo de cierta permanencia, así como las estrategias de gestión del personal conspiraban en muchas ocasiones contra la posibilidad de dinamizar estas relaciones. En distintas empresas el horario del comedor, por ejemplo, es diferente para unos y para otros trabajadores.

Entre otras acciones que este colectivo laboral emprendiera con respecto a los trabajadores contratados se destacan una serie de medidas encaradas desde el año 2008 frente a los despidos o cese de actividad de aquellos que se encontraban bajo la modalidad de trabajo eventual. En principio se logró la efectivización de 40 trabajadores que habían prestado servicio como contratados por varios años en la planta. Hasta allí, de todos modos, los despidos o cesación de actividades de parte de la empresa para con estos trabajadores era una situación de cierta frecuencia.

Durante el año 2009 continuaron los despidos de los trabajadores que restaban por contrato. Una porción de los mismos llegó a un acuerdo con la empresa a través del pago de una indemnización por un manto bastante mayor al que les hubiera correspondido formalmente, pero restó un grupo de aproximadamente 20 trabajadores que quisieron permanecer en la planta con un contrato efectivo. Ello dio comienzo a una se- 
rie de reuniones en el Ministerio de Trabajo de la Provincia de Buenos Aires hacia fines del año 2009 estimuladas por la CI, para resolver esta situación a favor de este grupo de trabajadores, demostrando que las contrataciones de aquellos habían sido fraudulentas: contratos por un período de tres años, en el mismo puesto de trabajo y en la misma empresa. El conflicto había adquirido ya cierta notoriedad fuera de los muros de la empresa, y en los medios de comunicación alternativos y de algunas organizaciones de izquierda bajo presión de la CI.

La seccional UOM Avellaneda acompañó a la CI y los trabajadores de este colectivo como demandante ante el Ministerio de Trabajo de la provincia. Si bien el Ministerio de Trabajo instó a la empresa a que regularice la situación de aquellos trabajadores debido a la extensión en el tiempo de los contratos, los mismos no fueron finalmente reincorporados.

En la planta de Siderar ubicada en el partido de Morón, Provincia de Buenos Aires, los delegados de base y los trabajadores emprendieron una serie de medidas básicamente desde el año 2002 en adelante que contuvieron a los trabajadores de las empresas tercerizadas que operaban en la planta como destinatarios de acciones colectivas contra la precariedad laboral.

A finales de los años 1990, según testimonios de trabajadores de esta empresa, el plantel se conformaba con alrededor de 150 trabajadores efectivos, 100 de empresas tercerizadas, y 50 de trabajadores eventuales contratados por agencias de empleo temporal. Ese número se había cambiado en 2008, básicamente porque el trabajo efectivo ascendió a 200 trabajadores, quedando solo 2 trabajadores contratados por agencia para suplir licencias en los meses de verano. El número de trabajadores de las empresas tercerizadas continuó en igual magnitud.

Con la renovación del cuerpo de delegados y la CI en el año 2002, y el ingreso de jóvenes trabajadores con un espíritu mas revulsivo en comparación a los delegados anteriores, se notó un cambio en la organización laboral interna. En primer lugar se motivó un proceso de socialización interna en vistas de generar relaciones solidarias entre trabajadores estables, contratados y de tercerizados, dado que los mismos, eran vistos por la mayoría de los trabajadores estables como 'empleados de segunda'. Esta tarea de concientización encarada por los delegados y trabajadores sensibilizados por esta problemática se invistió de una relevancia singular en la búsqueda por igualar condiciones económicas y de trabajos al interior de la planta.

En esta orientación, una de las primeras medidas encaradas por el cuerpo de delegados fue motorizar un proceso de organización gremial de los trabajadores tercerizados, comenzando por la unificación de los mismos bajo el convenio de la Unión Obrera Metalúrgica dado que, hasta ese momento, la filiación sindical y el convenio de trabajo de los mismos era diferente, siendo algunos de la Unión Obrera de la Construcción de la República Argentina. Esto no fue encarado por los delegados a partir de medidas de conflicto agresivas, sino a través de mecanismos constantes de presión hacia la empresa, habida cuenta de la oposición de la misma, y la falta de apoyo de la seccional gremial de la UOM - según nos testimonian - para acompañar estas demandas.

Así, a través de la intervención periódica de los delegados y trabajadores más activos de este colectivo, se fueron alentando mejoras para los tercerizados con el apoyo progresivo de toda la planta. Esta presión, según nos argumentan, sumada a una preocupación de la empresa por las relaciones gremiales internas, confluyó en una serie de mejoras para los trabajadores precarizados.

Una de ellas fue la estabilización de los trabajadores de las empresas tercerizadas en su puesto de trabajo. Acostumbrados a la rotación y al cambio de lugar de trabajo cuando una empresa de estas características dejaba de prestar sus servicios en Siderar, las acciones de los delegados en la planta tuvieron como efecto que los trabajadores pudieran permanecer en Siderar aunque la empresa tercerizada cambiara de firma, además de obligarlas a mantener la antigüedad de estos trabajadores.

Otra acción emprendida por los delegados de Siderar fue la promoción de la organización gremial interna de los trabajadores tercerizados, logrando que cada una de ellas pudiera nombrar delegados, dinamizando al mismo tiempo al interior de alguna de estas empresas, la metodología de las asambleas. Ello incentivó una serie de cambios y la obtención de ciertos beneficios y demandas postergadas para estos grupos de trabajo. Entre ellos se destaca el acceso a refrigerio, ropa de trabajo, elementos de seguridad, mejoras de salario, la no realización de determinadas tareas laborales.

A pesar de los logros y las conquistas logradas con el apoyo de la comisión interna y trabajadores estables, las desigualdades con los tercerizados se distinguían en una serie de beneficios a los que estos últimos no podían acceder, como los préstamos de materiales para la construcción que Siderar otorga a sus trabajadores estables.

En este colectivo de trabajo, la relación entre los delegados de Siderar y las empresas resultó en consecuencia fundamental para que las condiciones de trabajo de los mismos pudieran mejorar progresivamente. Desde su traspaso al convenio de la UOM, la organización gremial interna de los tercerizados, y la obtención progresiva de ciertos beneficios no tan solo materiales, sino además de reconocimiento de derechos y aprendizaje político, fue encabezada por los delegados de planta y en particular, en el contexto de un recambio en la comisión interna tras el ingreso de una generación de trabajadores con mayor impulso para estas acciones. 
El cambio en el contexto político, social y económico del milenio actual también acompañó la posibilidad de que el conjunto de acciones emprendidas pudiera encontrar viabilidad en la práctica. De todos modos, este contexto por sí mismo no promueve estas acciones, ya que las mismas han sido muy atomizadas en la actividad industrial, habida cuenta de que el sindicato resultó renuente en este caso en acompañar esta clase de acciones colectivas.

\section{Los trabajadores de la alimentación}

Los otros colectivos de trabajo que emprendieron demandas y acciones de base con respecto a la precariedad en este sector de la industria son los pertenecientes a las empresas Kraft Food Argentina y Pepsi$\mathrm{co}^{11}$, siendo las mismas empresas multinacionales que producen alimentos de consumo diario con una fuerte presencia en el mercado local.

Para el año 2009, Kraft-Food en Gral Pacheco ya no contaba con ningún trabajador eventual contratado por medio de las agencias de empleo o por contrato a tiempo determinado directo de fábrica. Sin embargo, y hasta entonces, esta empresa había utilizado esta modalidad de contratación de una manera usual y frecuente. La política de esta empresa a partir de la adquisición de Nabisco en el año 2001, según testimonios de los trabajadores entrevistados, fue la de nutrirse de un plantel de puestos claves ocupados por personal con contrato efectivo, incorporando el resto del personal a través de contratos eventuales. De este modo, se designaban personas con mayor experiencia y calificación para el manejo de algunos procesos productivos claves, quedando el resto del plantel conformado por operarios que desarrollaran tareas simples y de escasa calificación.

Hasta el año 2007, momento en el cual la empresa habría comenzado a modificar su política hacia los contratados, en parte por las presiones de los trabajadores de base, la rotación de personal era una situación constante, considerando que en la década actual los niveles productivos de esta empresa han resultado positivos. Por lo tanto, el personal temporario y eventual que transitaba por la empresa comenzó a notar en los mecanismos de contratación y rotación de personal, una estrategia que no obedecía a los descensos y ascensos productivos, sino a una estrategia de gestión de los recursos humanos que ocultaba la existencia, como manifiestan trabajadores de ésta y otras empresas, de puestos de trabajo genuinos y con posibilidad de efectivización del personal.

Esta política acentuaba los problemas de fragmentación al interior del colectivo laboral, advirtiéndose situaciones que acentuaban condiciones de desigualdad material, cultural y simbólica en este agrupamiento. Las condiciones de trabajo resultaban incluso más virulentas para los trabajadores contratados que debían afrontar mayores tareas y exigencias disciplinares respecto a los tiempos de trabajo y los tiempos de descanso.

Las diferencias entre trabajadores estables y contratados se notaban por otro lado en la percepción de los salarios. Al ingresar en categorías mínimas, los trabajadores eventuales recibían un salario menor al de los estables habiendo realizado muchas veces iguales tareas, e incluso aquellas que correspondían a las categorías salariales superiores.

En el lugar de trabajo, la división entre trabajadores con categorías contractuales diferentes generaba dificultades para establecer lazos secundarios duraderos que otrora caracterizaba el paso por los lugares de trabajo, condicionando las relaciones de cooperación y sociabilidad que caracteriza estos espacios. Para unos, la figura del trabajador estable se inviste de una meta y una aspiración para evitar la continua rotación y la dificultad que ello entraña por sus efectos materiales y sociales sobre las condiciones vitales y laborales. Para otros, el trabajador contratado se convierte en parte de una escenografía que cambia con frecuencia, por lo pronto en este tipo de empresas, dificultando la recreación de lazos solidarios de clase.

En este marco, entre los años 2007 y 2008 se sucedieron un conjunto de situaciones y medidas de los trabajadores contratados apoyados por los delegados de la comisión interna y progresivamente por parte de los trabajadores efectivos, en la búsqueda de su incorporación como trabajadores permanentes de KRAFT.

Con anterioridad a ello, algunas camadas de trabajadores con contrato por agencia primero, y con un contrato por tiempo determinado de fábrica después, fueron quedando efectivos. En algunas ocasiones no se produjeron medidas conflictivas y de lucha explícita, siendo ello fruto de todos modos de una organización en el lugar de trabajo que había estimulado asambleas gremiales, favoreciendo con ello un proceso de cuestionamiento y demanda sobre la situación y la condición de estos trabajadores.

En otras ocasiones se generaron acciones más disruptivas, como la de un grupo de trabajadores contratados que ingresó por la fuerza a la fábrica saltando los molinetes de la entrada y exigiendo su reincorpo-

11 La planta de Gral. Pacheco donde surgieron las acciones estudiadas contaba hacia el año 2009 con un plantel de 2.600 trabajadores (60\% mujeres y un $40 \%$ hombres, según nos informan trabajadores de la empresa). Los trabajadores de estas empresas se encuentran organizados en el Sindicato de Trabajadores de la Industria de la Alimentación (STIA). 
ración como trabajadores estables. En este caso, la demanda obtuvo resultados favorables. Ello no se produjo sin resistencias por parte del personal de seguridad de la fábrica, ni por parte de los de representantes del sindicato - congresales - que se hallaban en la planta. Estos se habrían negado - según nos testimonian-a responder por estos trabajadores en conflicto alegando que, al ser de agencia, no correspondía a la organización gremial manejar esta situación. Un paro de actividades en el turno noche contribuyó a revertir la situación de estos trabajadores contratados y efectivizarlos como personal de la empresa. Se menciona conjuntamente la toma del comedor en un conflicto por reincorporación de trabajadores contratados, y el aprovechamiento de una negociación en paritarias por salarios para movilizar a los efectivos en una demanda colectiva que incluyera mejoras económicas para unos, y estabilización laboral para otros.

Estas situaciones conflictivas o de reclamos fueron incentivadas por un proceso de desnaturalización que conlleva a la generación de un sentimiento de cansancio, y que en algunos casos se expresa en situaciones de confrontación manifiesta por parte de los trabajadores con contratos flexibles de fábrica y por agencia. La ocurrencia de estos eventos reconoce una serie de dimensiones que se combinaron en esta experiencia - como en otras - para dar cabida a este conjunto de reivindicaciones. De un lado, el ingreso como trabajadores contratados de grupos de jóvenes que comenzaron a transitar o a consolidar sus experiencias de trabajo en un contexto de flexibilidad, eventualidad y precariedad contractual en un escenario caracterizado por mejoras sustanciales en la economía argentina, en el empleo, y en el sector de la alimentación. Muchos de estos jóvenes reconocían en los antecedentes conflictivos del 2001 un estímulo que planteaba un contexto diferente para pensar, a través de situaciones de lucha, la trasmutación de su condición laboral vulnerable. Sin embargo, se sumaron a otros elementos que acompañaron y foguearon las demandas y los conflictos: entre ellos puede destacarse la presencia de una comisión interna que desde hacía más de una década se mostraba como una opción diferente a la posición del sindicato de la alimentación, entre otras cuestiones en lo que se refiere a su permeabilidad en la realización de asambleas y en la posición favorable en defensa de algunos conflictos y situaciones proble- máticas enfrentadas por los trabajadores contratados y de agencia. Y dentro de esta comisión interna, integrada hasta el año 2009, mayoritariamente por delegados afines a la Corriente Clasista y Combativa, fue adquiriendo presencia un referente proveniente de un partido de izquierda: el Partido de Trabajadores Socialistas (PTS). ${ }^{12}$

En la empresa Pepisco encontramos varios rasgos comunes a los analizados respecto de las experiencias y acciones encaradas por los trabajadores de Kraft, así como algunos elementos que se agregan a la información consignada anteriormente.

En su sede administrativa y de producción ubicada en la localidad de Florida, Provincia de Buenos Aires, se encuentra la única comisión interna de delegados que contiene esta empresa en sus filiales de América Latina. Este órgano de representación se formó en 1996. En 2007 ganó las elecciones internas, la lista integrada con varios miembros que posteriormente se vincularon con la agrupación "Desde Abajo". Los integrantes de la CI se renovaron en el 2009, manteniendo esta agrupación una importante representación al interior de este espacio gremial.

En la planta de Florida trabajan aproximadamente 500 empleados, en su mayoría entre 25 y 40 años de edad. Alrededor de un tercio de este plantel corresponde a personas contratadas mediante empresas eventuales.

Una primera situación conflictiva en relación a la problemática de las contrataciones precarias se produjo hacia fines del 2001, ante el despido de alrededor de 100 trabajadores - en su mayoría mujeres - que se encontraban en esta condición. En aquel momento la $\mathrm{CI}$, que se hallaba unida frente al reclamo de la efectivización de los trabajadores acompañó estas demandas. De este grupo, entre 20 y 30 trabajadoras se amotinaron entonces al interior de la planta negándose a salir. El turno noche, al ingresar a la planta, decidió apoyar este reclamo a través de un paro de actividades parcial decidido en asamblea. Pero el temor infundido por la empresa especialmente a las operarias, tomando nombre y apellido de los que no estaban cumpliendo con sus tareas en la línea de producción, fragilizó la medida.

Ante esta situación, el grupo de trabajadoras en conflicto por su reintegración organizó una tienda de campaña a las puertas de la fábrica para reclamar por su condición. Este conflicto duró aproximadamente dos

12 En el sector de la alimentación, militantes y trabajadores que adhieren o simpatizan con esta corriente política, han encontrado un espacio de expresión y protagonismo en las comisiones internas de delegados en algunas de las fábricas más importantes del sector. Con esta meta, el PTS impulsó la creación de la agrupación político-sindical "Desde abajo" que data de principios del año 2008 . Esta agrupación, integrada por militantes de este partido que trabajan en las fábricas de la alimentación (Kraft, Pepsico y Stany), otros trabajadores simpatizantes del PTS y otros de orientación política independiente, contiene como objetivos los reclamos por aumento de salario, mejoras en las condiciones de trabajo, efectivización de los trabajadores que ingresan por agencia o contrato directo de fábrica, el pase a planta permanente de los trabajadores tercerizados. En términos de organización gremial, esta agrupación persigue integrar las Cl de las fábricas del sector para luego disputar a la lista oficialista la conducción del sindicato que agrupa a estas fábricas 
meses, habiendo obtenido en ese tiempo la solidaridad de vecinos, y organizaciones sociales que asistieron a los portones de Pepsico manifestándose en contra de los despidos de estas trabajadoras. El escenario societal inaugurado con la crisis de diciembre de 2001 acompañó el clima de solidaridades de sectores medios y populares que apoyó este conflicto.

Finalmente y al cabo de dos meses, las mismas trabajadoras despedidas decidieron levantar la tienda y dar por finalizada la etapa de lucha. Si bien las solidaridades recibidas de distintos actores fue algo concreto, la persecución que había implementado la empresa para con los trabajadores efectivos que apoyaban el conflicto había diezmado y complicado el apoyo del propio colectivo laboral. Ello, junto a la fractura de la CI en torno a cómo resolver este conflicto, y la falta de apoyo del sindicato, se combinó para concluir con las medidas de protesta implantadas por las trabajadoras despedidas, y los efectivos que les prestaron su apoyo.

Desde el año 2002, y luego de la ocurrencia de este conflicto, Pepsico no contrató más trabajadores eventuales en forma directa, sino que recurrió a los contratos de trabajadores eventuales por agencias de empleo.

A partir del año 2007 fundamentalmente, y con el cambio en la orientación político gremial de la CI, las demandas y los reclamos por las condiciones de trabajo desiguales y por la efectivización de los trabajadores contratados por agencia se colocaron como temática central en la agenda de las acciones en el lugar de trabajo. Ello fue promovido básicamente por las inquietudes de los integrantes de la CI y trabajadores de base, algunos con trayectoria de militancia en partidos de izquierda como el PTS, otros desde una actitud política independiente y autónoma. El sindicato del sector, hasta tiempos muy recientes continuó con su actitud de distanciamiento respecto a la problemática de estos trabajadores.

Entre las desigualdades advertidas que los delegados buscaron problematizar de destacan algunas de tipo materiales, como el tema de los salarios, siendo éstos mayores para los efectivos que para los contratados, básicamente porque los primeros cobran un plus salarial por premios relacionados con la puntualidad, el presentismo, la productividad ${ }^{13}$.

Ante las demandas de la CI por igualación y equiparación salarial, la empresa respondió con una negativa a igualar el nivel a los trabajadores contratados y los efectivos, argumentando que estos últimos permanecían en la empresa durante todo el año, mientras los contratados solo lo hacían por un período corto.

Allí se presenta uno de los nudos problemáticos más importantes que sustentaban los reclamos de la CI desde el 2007 para demandar y presionar por la efectivización de los contratados. Además de bregar por la igualdad de condiciones entre unos y otros, que realizan igual tarea con igual responsabilidad, el reclamo se ligaba con la existencia de puestos de trabajo que son constantes en la producción y son ocupados por trabajadores eventuales, como si fueran éstos puestos oscilantes conforme al proceso productivo. En este sentido, los puestos de trabajo funcionaban durante todo el año, adquiriendo el reclamo por la efectivización no solamente una preocupación en torno a la inestabilidad e imprevisibilidad que afecta a los propios trabajadores eventuales, sino alegando la existencia de puestos de trabajo genuinos que requieren la efectivización del personal, y no su rotación permanente.

De esta manera, los delegados y trabajadores de esta empresa observaban que el plantel total nunca variaba, sino que se iban renovando grupos de trabajadores, pero siempre en iguales cantidades. A partir de un relevamiento que realizó la CI de todos los trabajadores de agencia, fueron advirtiendo que la empresa renovaba mensualmente alrededor de 20 a 30 trabajadores, dando de alta y baja a la misma cantidad de empleados.

Organizar a los trabajadores contratados para demandar por sus condiciones de trabajo y contratación, así como concitar la solidaridad de parte de los efectivos con los trabajadores en esta condición, no es una tarea sencilla, sino por demás compleja. Tarea que reclama un importante proceso de concientización de parte de los delegados, militantes y trabajadores que consideran fundamental reorganizar estas solidaridades en el lugar de trabajo, afrontando los miedos, las diferencias e incluso ciertas prácticas de discriminación que emergen entre los propios trabajadores.

Entre los trabajadores contratados, el temor a la represalia empresarial, la falta de confianza y de experiencia y roce con la práctica gremial y política en torno a la defensa de derechos colectivos se esgrime como una problemática que limita o dificulta la organización. Pero la rotación y la inestabilidad laboral convencen a algunos de tratar de subvertir su condición, más aún si encuentran en la organización gremial interna un estímulo para ello.

De todas maneras, el miedo a involucrarse en acciones de protesta y reclamos caracteriza tanto a unos como a otros trabajadores con condiciones contractuales diferentes. La amenaza del desempleo de los años 1990 que caracterizó a la argentina, y la dificultad de muchos delegados y comisiones internas de fábrica para activar demandas y motorizar conflictos y disputas en torno a los derechos laborales, imprimió una marca en los lugares de trabajo que no resulta fácil de quitar. Ello claro, considerando la diferencia entre 
los sectores de actividad económica, los gremios y las tradiciones de militancia de cada una de las fábricas.

A esto se suman las políticas de las empresas que han utilizado en parte esta modalidad de fragmentación contractual en los lugares de trabajo no solamente con finalidades económicas, sino en muchos casos como una modalidad de fragilizar políticamente a los sindicatos y a las organizaciones gremiales de base. Insistimos por supuesto en la necesidad, para el caso argentino, de ponderar esta argumentación considerando distintas experiencias, tradiciones y modalidades organizativas sindicales.

Entre los conflictos encarados por la CI y trabajadores de la planta frente a la desigualdad de condiciones de trabajo entre contratados y efectivos, se destaca así mismo el ocurrido en el año 2007 cuando se obtuvo un plus salarial para todos los trabajadores de la planta, incluso de los de las empresas tercerizadas. Ello si bien, no se pudo conseguir el mismo monto para todos.

En los últimos años la CI ha encarado paralelamente una serie de denuncias realizadas al Ministerio de Trabajo acusando a la empresa de cometer fraude laboral, al tomar personal temporario para realizar trabajos de producción que se desarrollan durante todo el año. Como denuncian los delegados, se observan maquinarias y líneas de producción que tienen un funcionamiento anual, pero a las que asignan personal eventual, justificando esta observación, la efectivización de los contratados que desarrollan estas tareas. $\mathrm{Al}$ momento de realizar las entrevistas, la CI ya había sido convocada a varias audiencias y reuniones en el Ministerio de Trabajo con el objetivo de incentivar la negociación entre los trabajadores y la empresa. Si bien los reclamos y las denuncias datan de varios años atrás, durante el año de 2009, la CI obtuvo la atención y la intervención de la institución pública.

Simultáneamente se producían las denuncias institucionales por parte de la CI, se desarrollaban asambleas y se asistía con frecuencia a la oficina de Recursos Humanos de la empresa con el fin de ejercer presión sobre la misma para que mantuviera al personal eventual con perspectivas de su efectivización, mientras que las audiencias y denuncias realizadas pudieran prosperar.

Desde la CI habían emprendido conjuntamente algunas medidas para presionar a la empresa respecto a la situación de los trabajadores de empresas tercerizadas que operaban en el interior de la planta. En este sentido, denuncian los delegados de Pepsico, solían presentarse frecuentemente problemas económicos y de maltrato laboral con los trabajadores de estas empresas. El sueldo de estos trabajadores era inferior al de los de la fábrica, denunciaban los delegados. Cuando Pepsico pagaba un plus salarial producto de presiones gremiales, los trabajadores tercerizados recibían menos que el monto de lo que percibían los efectivos. También le exigían a la empresa que les entregara herramientas de trabajo, las cuales solían ser en ocasiones deficitarias. El problema en estos casos no es el trabajo eventual, ya que en general los empleados de las empresas tercerizadas son efectivizados luego de tres meses de prueba, sino las diferencias entre los ingresos y las condiciones de trabajo de los que son empleados directamente por Pepsico, y los que son contratados por terceras empresas que prestan servicios a través de su personal en la misma planta ${ }^{14}$.

\section{Reflexiones finales}

Para elaborar el presente artículo hemos privilegiado una inquietud que ha recorrido estas páginas: de qué modos, en qué sentidos, con qué limitaciones y potencialidades, colectivos de trabajo basistas han encarado un conjunto de medidas para hacer frente a las problemáticas de integración sociolaboral que reproducen el proceso de individualización de experiencias profesionales y de trabajo.

En efecto, la precariedad laboral como una condición destacable de las relaciones laborales que ha tendido a amplificarse desde hace unas décadas atrás en las economías occidentales, y en la Argentina, acentúa trayectorias laborales fragmentadas, heterogéneas, y que fomentan modalidades individuales y privadas de lidiar con los riesgos materiales, culturales y simbólicos que contiene esta modalidad de integración socio laboral.

Las contrataciones eventuales, intermitentes, inciertas, la elevada rotación en el puesto de trabajo, la dificultad de reconfigurar lasos secundarios en el ámbito de trabajo, de ligarse con las organizaciones de representación sindical, de consolidar una identidad profesional y de clase, caracterizan al trabajo precario.

Las condiciones de tránsito desigual por el espacio productivo que se distingue entre trabajadores con modalidades de vinculación diferente en el lugar de trabajo, han buscado ser reflexionadas, desnaturalizadas, y encaradas, por delegados y trabajadores de base de algunos sectores de la economía industrial, y en particular de algunos colectivos de trabajo. Como hemos

14 La Ley de Contrato de Trabajo estipula que las empresas que contraten servicios de terceros con vistas a proporcionarlos en la propia empresa responden solidariamente por las obligaciones emergentes de la relación laboral. (Art. 29, según Ley 24.013). Ello fue el sustento de la acción emprendida recientemente en el país, en agosto de 2010, por el Sindicato de Camioneros ante la empresa Techint exigiendo el blanqueo de aproximadamente 5000 transportistas que trabajan para esta empresa de forma tercerizada. 
destacado, esta problemática no resultó mayormente encarada por las organizaciones sindicales más amplias, conformándose así un vacío en la representación y la defensa de los derechos laborales de los trabajadores con contrataciones eventuales y/ó tercerizados.

Así, una demanda colectiva, pero presente en ciertos ámbitos productivos específicos ha encontrado significativas dificultades para transmutar en demanda sindical general y amplificar su potencialidad de reversión.

Cuando los reclamos y las preocupaciones se hicieron presentes, tal como relatamos en páginas precedentes, el estímulo de algunos tradiciones gremiales en el caso de los trabajadores metalúrgicos, por ejemplo, o de algunas orientaciones partidarias principalmente de la izquierda, como en el caso de los trabajadores de la alimentación, que fue vital para dinamizar demandas y acciones relativas a las contrataciones precarias en la industria.

Un escenario económico, político y societal inaugurado luego de la crisis sistémica del año 2001 en el país permeó la potencialidad de estas experiencias. De hecho, los lugares de trabajo ya no revistieron este carácter expulsivo de la mano de obra que caracterizó la década de los 90 en nuestro país. Nuevas generaciones de trabajadores, con escasa trayectoria laboral, sindical o política nutrieron los colectivos de trabajo y fueron además los principales afectados por las modalidades de contratación precaria. En algunos, la inspiración de revulsión y trasmutación de estas condiciones motivó la participación en los reclamos y demandas. Estos grupos, junto con algunos trabajadores con mayor experiencia política y sindical, confluyeron para dinamizar cuestionamientos y acciones en torno a la precariedad.

La permeabilidad de las empresas para incorporar algunos de estos reclamos en este nuevo contexto es advertible, pero se destaca asimismo, a la continuidad en muchas de las mismas por aprovechar el marco legal y regulatorio que el proceso de flexibilización laboral favoreció para contar con aquella fuerza de trabajo que puede ser atraída, o expulsada, conforme a los vaivenes productivos. De todas maneras, aquí se distinguen una serie de señalamientos de importancia: muchas de las empresas han excedido legalmente el marco regulatorio que favorece las contrataciones precarias extendiendo los tiempos laborales adicionales a los previstos legalmente. Conjuntamente, varias de aquellas han ocupado puestos de trabajo que muestran cierta permanencia en la producción con la figura del trabajo eventual. Estas situaciones han sido advertidas por los delegados y colectivos basistas justificando las acciones emprendidas para lidiar con esta problemática.

Al interior de los colectivos laborales diversas cuestiones concitan al mismo tiempo la preocupación y el interés de los delegados y trabajadores más activos gremialmente: ello se refiere a cómo estimular las solidaridades laborales en el marco de la fragmentación de la fuerza de trabajo. En ello, como promover las vinculaciones y relaciones entre los trabajadores efectivos, contratados y tercerizados reconstruyendo solidaridades que los estimule a lidiar colectivamente con los derechos laborales lacerados y las desigualdades entre unos y otros inspira y problematiza a quienes buscan dinamizar estos acercamientos.

\section{Referencias}

ALVATER, E.; MAHNKOPF, B. La globalización de la inseguridad: t. Trabajo en negro, dinero sucio y política informal, .Paidós Entornos, Buenos Aires: Paidós Entornos, 2008.

AZPIAZU, D.; SCHORR, M. Hecho en Argentina: industria y economía, 1976-2007. Siglo XXI, Buenos Aires: Siglo XXI, 2010.

CASTEL, R. ¿Por qué la clase obrera perdió la partida? Marx 2000. Las nuevas relaciones de clases. In: CONGRESO MARX INTERNACIONAL II, Buenos Aires, 2000. CENTRAL DE LOS TRABAJADORES ARGENTINOS.Informe sobre conflictividad laboral, Observatorio del Derecho Social, Buenos Aires, 2007, 2008, 2009. Disponível em: <http://www.cta.org.arwww.cta.org.ar>. Acesso em: 2010 .

CONTRATO DE TRABAJO, Ley n. 20.744 actualizada. Buenos Aires: Ediciones del País, 2009.

FELDMAN, S.; GALÍN, P. Introducción. In: GALÍN; Y NOVICK (Comps.). La precarización del empleo en Argentina. Buenos Aires: CEAL, OIT, CLACSO, 1990.
HARVEY, D. La condición de la posmodernidad. Investigación sobre los orígenes del cambio cultural. Buenos Aires: Amorrortu, 1990.

INFORME DE PROSPERAR, 2010. Disponível em: $<$ http://www.prosperar.gov.arwww.prosperar.gov.ar $>$. Acesso em: 2010.

PERELMAN, L. El empleo no permanente en la Argentina. Revista Desarrollo Económico, Buenos Aires, v. 41, n. 161, 2001. RODGERS, G. El debate sobre el trabajo precario en Europa Occidental. En: RODGERS, Gerry; JANINE. (Comps.). El trabajo precario en la regulación del mercado laboral: crecimiento del empleo atípico en Europa Occidental. España: OIT, Ministerio de Trabajo, Empleo y Seguridad Social, 1992.

SITE Kraft Food: Disponível em: <http://www.kraftfoods. com.arwww.kraftfoods.com.ar>. Acesso em: 2010.

SITE Pepsico: Disponível em: <http://www.pepsicosnacks. com.arwww.pepsicosnacks.com.ar>. Acesso em: 2010.

SVAMPA, M. La sociedad excluyente: la Argentina bajo el signo del neoliberalismo, Buenos Aires: Taurus, 2005. 


\title{
Base trade union and precarious work in Argentina industry: review of some experiences
}

\begin{abstract}
This article analyses the base trade unions requests and actions on the issue of precarious work that emerged in the industrial sector of Argentina's economy in the current millennium. It fundamentally seeks to analyze in which sense, with what attributes, potentiality and limitations conflicting requests and actions have been developed on this subject stimulated by base delegates and workers. This concern recognizes the importance of a context caracterized by the vitalization of trade union conflicts and the persistence of socio-occupational integration modalities, which are inequal inside groups of workers.

Under this concern, we present the analysis of four base collectives in the industry who have faced lawsuits and actions around the problem of insecurity, particularly with respect to temporary employees and THA workers. These groups are in the food industry and in the metallurgical sector.
\end{abstract}

Keywords: precarious work; collective request and action; base trade union; industrial sector; Argentina.

\section{Ação sindical de base e precariedade do trabalho na indústria Argentina: revisão de algumas experiências}

\begin{abstract}
Resumo
Este artigo analisa as demandas e ações sindicais de base em torno da problemática da precariedade do trabalho que emergiram no setor industrial da economia Argentina no milênio atual. Propõe-se analisar principalmente em que sentidos, com que atributos, potencialidades e limitações se desenvolveram demandas e ações conflitantes em torno desta temática estimuladas por delegados e trabalhadores de base. Esta inquietude reconhece a importância de um contexto caracterizado pelo crescimento dos conflitos sindicais e a persistência de modalidades de integração sociolaboral desiguais ao interior dos coletivos trabalhistas. Em virtude desta preocupação, apresenta-se a análise de quatro coletivos de base na indústria que encararam demandas e ações em torno da problemática da precariedade, em particular a respeito dos contratos de trabalho eventuais e os trabalhadores terceirizados. Estes coletivos fazem parte do setor metalúrgico e da alimentação.
\end{abstract}

Palavras-chave: precariedade do trabalho, demandas e ação coletiva, sindicalismo de base, setor industrial, Argentina.

Data de recebimento do artigo: 19-11-2010

Data de aprovação do artigo: 25-01-2011 